\title{
Team adaptation to an unforeseen system failure: Limits of the potential aids of shared knowledge and standardized communication.
}

Citation for published version (APA):

Sander, P. C., van Doorn, R. R. A., van der Pal, J., \& Zijlstra, F. R. H. (2015). Team adaptation to an unforeseen system failure: Limits of the potential aids of shared knowledge and standardized communication. European Journal of Work and Organizational Psychology, 24(5), 796-811. https://doi.org/10.1080/1359432X.2015.1006199

Document status and date:

Published: 03/09/2015

DOI:

10.1080/1359432X.2015.1006199

Document Version:

Publisher's PDF, also known as Version of record

Document license:

Taverne

Please check the document version of this publication:

- A submitted manuscript is the version of the article upon submission and before peer-review. There can be important differences between the submitted version and the official published version of record.

People interested in the research are advised to contact the author for the final version of the publication, or visit the DOI to the publisher's website.

- The final author version and the galley proof are versions of the publication after peer review.

- The final published version features the final layout of the paper including the volume, issue and page numbers.

Link to publication

\footnotetext{
General rights rights.

- You may freely distribute the URL identifying the publication in the public portal. please follow below link for the End User Agreement:

www.umlib.nl/taverne-license

Take down policy

If you believe that this document breaches copyright please contact us at:

repository@maastrichtuniversity.nl

providing details and we will investigate your claim.
}

Copyright and moral rights for the publications made accessible in the public portal are retained by the authors and/or other copyright owners and it is a condition of accessing publications that users recognise and abide by the legal requirements associated with these

- Users may download and print one copy of any publication from the public portal for the purpose of private study or research.

- You may not further distribute the material or use it for any profit-making activity or commercial gain

If the publication is distributed under the terms of Article $25 \mathrm{fa}$ of the Dutch Copyright Act, indicated by the "Taverne" license above, 


\section{European Journal of Work and Organizational Psychology}

\section{Team adaptation to an unforeseen system failure: Limits of the potential aids of shared knowledge and standardized communication}

Pia C. Sander, Robert R. A. van Doorn, Jelke van der Pal \& Fred R. H. Zijlstra

To cite this article: Pia C. Sander, Robert R. A. van Doorn, Jelke van der Pal \& Fred R. H. Zijlstra (2015) Team adaptation to an unforeseen system failure: Limits of the potential aids of shared knowledge and standardized communication, European Journal of Work and Organizational Psychology, 24:5, 796-811, DOI: 10.1080/1359432X.2015.1006199

To link to this article: https://doi.org/10.1080/1359432X.2015.1006199

Published online: 05 Feb 2015.

Submit your article to this journal $\sqsubset$

Џll Article views: 753

Q

View related articles $₫$

View Crossmark data \lceil

Citing articles: 4 View citing articles $匚$ 


\title{
Team adaptation to an unforeseen system failure: Limits of the potential aids of shared knowledge and standardized communication
}

\author{
Pia C. Sander ${ }^{1}$, Robert R. A. van Doorn ${ }^{2}$, Jelke van der Pal ${ }^{1}$, and Fred R. H. Zijlstra ${ }^{2}$ \\ ${ }^{1}$ Department of Training, Simulation and Operator Performance, National Aerospace Laboratory NLR, Amsterdam, The \\ Netherlands \\ ${ }^{2}$ Faculty of Psychology and Neuroscience, Department of Work and Social Psychology, Maastricht University, \\ Maastricht, The Netherlands
}

\begin{abstract}
The present study investigates the potential benefits of a team's shared knowledge and standardized communication in adapting to an unforeseen change by combining literature on adaptation and team performance. Each of 20 teams performed a dynamic team task and was suddenly confronted with a simulated partial system breakdown. Results show that a methodological framework designed to describe performance adaptation to an unforeseen change in individuals can also be used to model performance adaptation in teams. The system failure was followed by a performance drop and a subsequent period of gradual performance recovery. Accuracy of teams' shared knowledge correlated positively with performance before and after the change, confirming and extending the literature on shared mental models. However, the amount of knowledge similarity did not aid teams in adapting to the unforeseen system breakdown. In addition, improving teams' standardized communication had no damping effect on the sudden performance drop and neither helped them during the subsequent recovery period. These results show that even though shared knowledge and efficient communication are of high value to team performance and success, these characteristics are limited in aiding adaptive team performance after unforeseen unique changes that force team members to update their strategies.
\end{abstract}

Keywords: Shared knowledge; Standardized communication; Unforeseen unique change; Continuous growth modelling.

The main issue in this study is how teams that differ in both shared knowledge and communication strategies adapt to unforeseen and unique changes in their task environment. An investigation of this issue is important as teams are often viewed as effective units to face changing and dynamic situations within organizations (Resick, Dickson, Mitchelson, Allison, \& Clark, 2010; Summers, Humphrey, \& Ferris, 2012). Teams are considered as essential for key decisions in varied settings such as hospital operating rooms, military units, sales production departments or air traffic control. These teams frequently operate in dynamic environments and have to be prepared to recognize, handle and adapt to changes in their work environment (e.g., Baard, Rench, \& Kozlowski, 2014; Burke, Stagl, Salas, Pierce, \& Kendall, 2006; Kontogiannis \& Malakis, 2013). To adapt to these critical changes, team members are believed to apply shared knowledge, mutual understanding, and efficient and often standardized communication (Kozlowski, Gully, Nason, \& Smith, 1999).

In all, it has been recognized that effective expert teams are able to handle sudden but frequent and therefore anticipated changes (Baard et al., 2014; Burke et al., 2006; Kozlowski et al., 1999). However, it is unknown whether this also applies to unforeseen and often unique changes. These latter changes (hereafter termed unforeseen changes) refer to substantial and often unique alterations in the task environment, such as partial or total system failures or breakdowns (Weick, 1985) that a team has no experience with. These dramatic changes in the task environment are often feared by many organizations (Bainbridge, 1983), and little knowledge exists on how teams adapt to such a situation and whether they can be aided in an effective way. The questions in the present study pertain to how team performance is affected by such low frequent and

Correspondence should be addressed to Pia C. Sander, Department of Training, Simulation and Operator Performance, National Aerospace Laboratory NLR, P.O. Box 90502, 1106 BM Amsterdam, The Netherlands. E-mail: Pia.Justen@nlr.nl

No potential conflict of interest was reported by the authors. 
unique system failures, and whether shared knowledge among team members and standardized communication help a team to adapt to these unforeseen changes.

Research on this topic is essential as an unsuccessful response to these events may have negative or even fatal consequences in a variety of work environments (Marks, Sabella, Burke, \& Zaccaro, 2002; cf. Stachowski, Kaplan, $\&$ Waller, 2009). The present study will approach this issue by combining the literature on adaptation to changes of individuals (Lang \& Bliese, 2009) and teams (Summers et al., 2012) with existing knowledge on team functioning in terms of shared knowledge (Burke et al., 2006; CannonBowers, Salas, \& Converse, 1993; Uitdewilligen, Waller, \& Zijlstra, 2010) and communication (Burke et al., 2006; Rosen et al., 2011; Stachowski et al., 2009). More specifically, whether a team experiences a sudden performance drop followed by a recovery phase when the team members face an unforeseen change in the task environment in the form of a unique partial system breakdown is tested. Such a performance pattern after an unforeseen change can be assumed on the basis of two notions, namely coordination flux (Summers et al., 2012) and phases of adaptation in individuals (Lang \& Bliese, 2009) as it will be explained in the next section.

The present study further tests recent theory (Burke et al., 2006; Rosen et al., 2011) by investigating whether shared knowledge and standardized communication within a team helps the team members to adapt more effectively to an unforeseen and unique change in the task environment. These aspects should aid adaptive team performance as team members should have a common understanding of the nature of the change and can communicate effectively about how to adapt to it (e.g., Randall, Resick, \& DeChurch, 2011)

\section{MODELLING ADAPTIVE TEAM PERFORMANCE: DISTINGUISHING ADAPTATION PHASES}

It is important to note that the observation of potential effects of an unforeseen change on team performance is only possible when the team is monitored over time (Ackerman, 1992; Burke et al., 2006; Murphy, 1989; Waller, 1999). An unforeseen unique change in the task environment at one point in time may have sudden but also subsequent gradual effects on team performance (e.g., Chan, 2000; Kozlowski et al., 1999; LePine, 2005; Randall et al., 2011). These temporary and temporal performance changes will be captured in the present study by applying a methodological framework, namely discontinuous growth modelling, which has been successfully used to study adaptive performance in individuals over time (Lang \& Bliese, 2009).

Discontinuous growth modelling allows specifically testing adaptation to an unforeseen change in the task environment during different phases of performance. These phases are an initial skill acquisition (SA) followed by two consecutive phases of adaptation. During initial SA a team becomes familiar with a new task and should gradually improve in performance (Ackerman, 1992). A subsequent unforeseen change in the task environment then requires the use of specific strategies that may not have been part of the team's repertoire prior to that change (Lang \& Bliese, 2009). This implies that such a change typically creates two phases within a team (Burke et al., 2006; Randall et al., 2011; Rosen et al., 2011). The first phase is characterized by a so-called coordination flux (Summers et al., 2012), which reflects a period of uncoordinated behaviour and confusion within the team that makes it difficult to reapply learned skills. During the second phase, team members manage to gradually overcome this period by subsequently developing new interaction patterns (Summers et al., 2012) and by establishing new behavioural or cognitive goal-directed actions (Burke et al., 2006; Rosen et al., 2011).

This study will first test whether these successive alterations in a team will become visible via a specific performance pattern over time. The unforeseen change should result into a visible initial performance drop referred to as transition adaptation (TA) (Lang \& Bliese, 2009) since learned behaviours and strategies fail in the new situation. This signifies the temporary coordination flux (Summers et al., 2012). While team members continue to perform the task, effective teams should develop new strategies and adjust their behaviour. This subsequent reacquisition adaptation (RA) becomes discernible via a gradual increase in performance and thus characterizes a second period of skills acquisition to adapt to the new situation (Burke et al., 2006; Rosen et al., 2011).

As discontinuous growth models have only been applied to individual performance adaptation (Lang \& Bliese, 2009), it is the first aim of the present study to add to the literature by testing whether the two successive adaptation phases are also discernible in adaptive team performance after an unforeseen change. Indeed performance tends to decrease temporarily in teams that experience a member change during task performance because established coordination patterns become inappropriate (Summers et al., 2012). We would expect a similar detrimental effect on performance after an unforeseen system breakdown because this requires re-evaluation of both coordination and task strategies. We specifically test whether teams perform worse immediately after the change compared to before the change (TA) and whether performance scores slowly increase again during subsequent task execution (RA). This leads to the first hypothesis:

Hypothesis 1: Team adaptation to an unforeseen change becomes visible in an initial drop in team performance (TA) followed by a performance increase (RA). 


\section{RELATIONSHIP BETWEEN ADAPTIVE TEAM PERFORMANCE AND SHARED KNOWLEDGE}

Discontinuous growth modelling also allows testing differences in characteristics of teams during each phase of adaptation. It therefore provides the methodological basis to investigate whether team adaptation to an unforeseen change is aided by shared knowledge among team members. Shared knowledge, which is also often referred to shared mental models, pertains to knowledge structures of team members that help them to interpret and explain the task and each other's behaviour in a similar and accurate manner (Cannon-Bowers \& Salas, 2001). The potential aid of shared mental models in adaptive team performance makes sense as they are generally viewed as essential for effective team performance (Burke et al., 2006; CannonBowers et al., 1993; Uitdewilligen et al., 2010). Studies show that shared knowledge that pertains to the task environment, but also to a team's functioning and interaction, positively affect team effectiveness (DeChurch \& MesmerMagnus, 2010; Mathieu, Heffner, Goodwin, Cannon Bowers, \& Salas, 2005). These shared knowledge structures, that in the present study pertain to task and team aspects, thus allow team members to have a similar understanding of the task and make it possible for team members to coordinate their actions accordingly (Marks, Mathieu, \& Zaccaro, 2001; Mohammed, Ferzandi, \& Hamilton, 2010).

To study the potential help of shared mental models among team members to team adaptation to an unforeseen change, it is important to distinguish between two apparent aspects of shared knowledge structures, namely similarity and accuracy. Mental model similarity refers to how compatible or consistent team members' knowledge is (Marks, Zaccaro, \& Mathieu, 2000), whereas mental model accuracy reflects the degree to which this knowledge represents reality (Edwards, Day, Arthur, \& Bell, 2006). This distinction is important as team members, for instance, may have a shared view about how to coordinate their work, yet being wrong about the efficiency of this coordination (Lim \& Klein, 2006). Moreover, prior research showed that mental model similarity positively relates to team members' perception of their effectiveness, whereas accuracy is related to actual team performance (Resick et al., 2010). Results about the role of both aspects with team performance remain inconsistent (Mohammed et al., 2010), which emphasizes the need to include both aspects in the present adaptation study.

When team members face a change in the task environment, mental model accuracy should help them to understand the nature of the change adequately and find effective strategies to handle the new situation (Randall et al., 2011). They have an accurate understanding of the consequences of these strategies and are able to choose and apply the best strategy for the specific situation. The degree of mental model accuracy may therefore eventually enable team members to adapt to unforeseen changes irrespective of the degree of mental model similarity.

Knowledge similarity further benefits adaptive performance as team members may quickly agree on one strategy and coordinate their actions more easily. It thus enables rapid strategy selection (Rico, Sánchez-Manzanares, Gil, \& Gibson, 2008) and should minimize the coordination flux in unforeseen situations (Summers et al., 2012). In addition, team members who have developed similar mental models in the past may have available more mental resources to assess a new task environment (Hockey, 1997; Kahneman, 1973; Rouse \& Morris, 1986). This benefits their ability to efficiently adjust their shared knowledge and adapt to the new situation (LePine, 2005).

These ideas about knowledge accuracy and similarity corroborate the conceptual model of team adaptation (Burke et al., 2006; Rosen et al., 2011) that envisions shared mental models as input and outcome of the adaptive cycle in response to a significant change in the environment. Burke et al. (2006) propose that shared knowledge should aid the assessment of the environment for salient cues, facilitate the formulation and execution of a plan, and eventually help the process of team adaptation. In fact, they suggest that proactive adaptation is impossible in the absence of shared mental models. Recent research has found first empirical evidence for these theoretical assumptions, as team members with similar and accurate mental models about strategic priorities and implications adjust existing strategies more effectively (Randall et al., 2011).

The present study tests this aspect of Burke et al.'s model of adaptation (Burke et al., 2006; Rosen et al., 2011) in terms of TA and RA (Lang \& Bliese, 2009) after an unforeseen partial system failure. Accordingly, it is expected that the performance drop after the change is less severe for teams with similar and accurate mental models and is followed by a faster recovery of task performance. This leads to the following two hypotheses:

Hypothesis 2: Mental model similarity negatively relates to the size of the initial performance drop after an unforeseen change and positively relates to the increase in performance after the unforeseen change.

Hypothesis 3: Mental model accuracy negatively relates to the size of the initial performance drop after an unforeseen change and positively relates to the increase in performance after the unforeseen change.

\section{EFFECTS OF STANDARDIZED COMMUNICATION ON TEAM ADAPTATION}

This study additionally tests whether standardized and systematic communication aids a team in adapting to an 
unforeseen and unique system failure. It is long known that successful teams communicate effectively and exchange information in a clear and accurate manner by using standardized terminology (Espevik, Johnsen, \& Eid, 2011; Kanki, Folk, \& Irwin, 1991; Kring, 2005; Xin \& Zhiming, 2005). This is especially important in procedure-driven and dynamic environments. Examples are air traffic control and firefighting (Cannon-Bowers \& Salas, 1998; Keyton \& Beck, 2010; Uitdewilligen, Waller, \& Pitariu, 2013). In fact, the failure to communicate in a structured way in these environments is a frequent cause of accidents (Malakis, Kontogiannis, \& Kirwan, 2010).

Of course, the effectiveness of established interaction patterns invariably decreases when the task context and/or the team settings are altered (Salas, Rosen, Held, \& Weissmuller, 2009; Stachowski et al., 2009; Wilson, Salas, Priest, \& Andrews, 2007). Team members then need to quickly re-adjust their communication behaviour to the new situation to sustain a sufficient level of team performance. In the present study, half of the teams are instructed to practice standardized communication prior to and to apply it during the experimental session. The main question is whether this instruction will help these teams after the unforeseen change in the task environment (Burke et al., 2006; Stachowski et al., 2009; Uitdewilligen et al., 2013).

One perspective on the role of standardized communication patterns in team adaptation asserts that successful team behaviour, including the use of standard terminology, does not aid adaptation after an unforeseen change (Gersick, 1988). This idea is based on assertions that existing communication patterns may become obsolete after the change (Stachowski et al., 2009). Indeed, an unforeseen change creates a coordination flux of unstructured interaction patterns in all teams (Summers et al., 2012). This may however be different in teams that practiced in advance to use standardized communication protocols, which are still (partly) beneficial after the unforeseen change.

Such an idea supports recent notions on team adaptation that assumes that communication plays a central role in adaptive team performance (Burke et al., 2006; Rosen et al., 2011; Stachowski et al., 2009). Accordingly, communication is an individual-level process that aids team members carrying out a new and adaptive plan, which consequently helps them to adapt effectively. Information should thereby be articulated in a clear and accurate manner and with proper terminology.

These ideas have been successfully applied in real teams, for example, to instruct aircraft crews in using communication protocols and as additional help in retaining information in memory, to aid team members in handling new situations (Salas, Wilson, \& Edens, 2009). In addition, members in teams with stable interaction patterns behave more predictably, which in turn should facilitate team adaptation to unforeseen changes (Kanki et al., 1991; LePine, 2005). The idea is that stable and especially standardized communication will be beneficial after the unforeseen change in providing a firm basis for a team to update knowledge and adapt skills to the new tasks. In other words, providing the means to a team to apply standardized communication prior to an unforeseen change should be beneficial after the change (Burke et al., 2006; Rosen et al., 2011). This leads to the final hypothesis:

Hypothesis 4: A team that uses standardized communication before an unforeseen change will display a smaller drop in performance after the unforeseen change followed by a faster increase in team performance.

In sum, this study on team adaptation to unforeseen changes tests four hypotheses based on contemporary notions of adaptive performance in individuals (Lang \& Bliese, 2009) and in teams (Baard et al., 2014; Burke et al., 2006; Rosen et al., 2011; Uitdewilligen et al., 2013). Figure 1 provides an overview of the experimental design including the hypothesized pattern of team performance before and after the unforeseen change, and the effects of shared knowledge and communication on adaptive team performance. Team performance is studied along three phases and is expected to follow a specific pattern (Hypothesis 1). In the first phase teams become acquainted to the new task environment, resulting in a marked team performance improvement over time, referred to as the initial acquisition phase.

It is investigated whether adaptive team performance after an unforeseen change can be in essence described by two subsequent phases, namely transition and RA. The establishment of the two phases in the literature on individual adaptation gives reason to hypothesize that a similar performance pattern is discernible in teams. The second and third hypotheses test whether shared knowledge within a team may be beneficial in team adaptation. We distinguish between similarity and accuracy of shared knowledge and expect that both mental model similarity (Hypothesis 2) and accuracy (Hypothesis 3) support adaptive team performance. The final hypothesis tests whether there are potential benefits of standardized communication to adaptive team performance (Hypothesis 4).

\section{METHOD}

\section{Participants and team assignment}

Sixty undergraduate psychology students (42 females) participated in an experiment for course credits or gift vouchers. Their average age was 20.37 years $(S D=2.03)$. Participants were randomly assigned to a team resulting in 20 teams with three members each. Every participant was assigned to one of three team roles within a team. Participants gave informed consent 

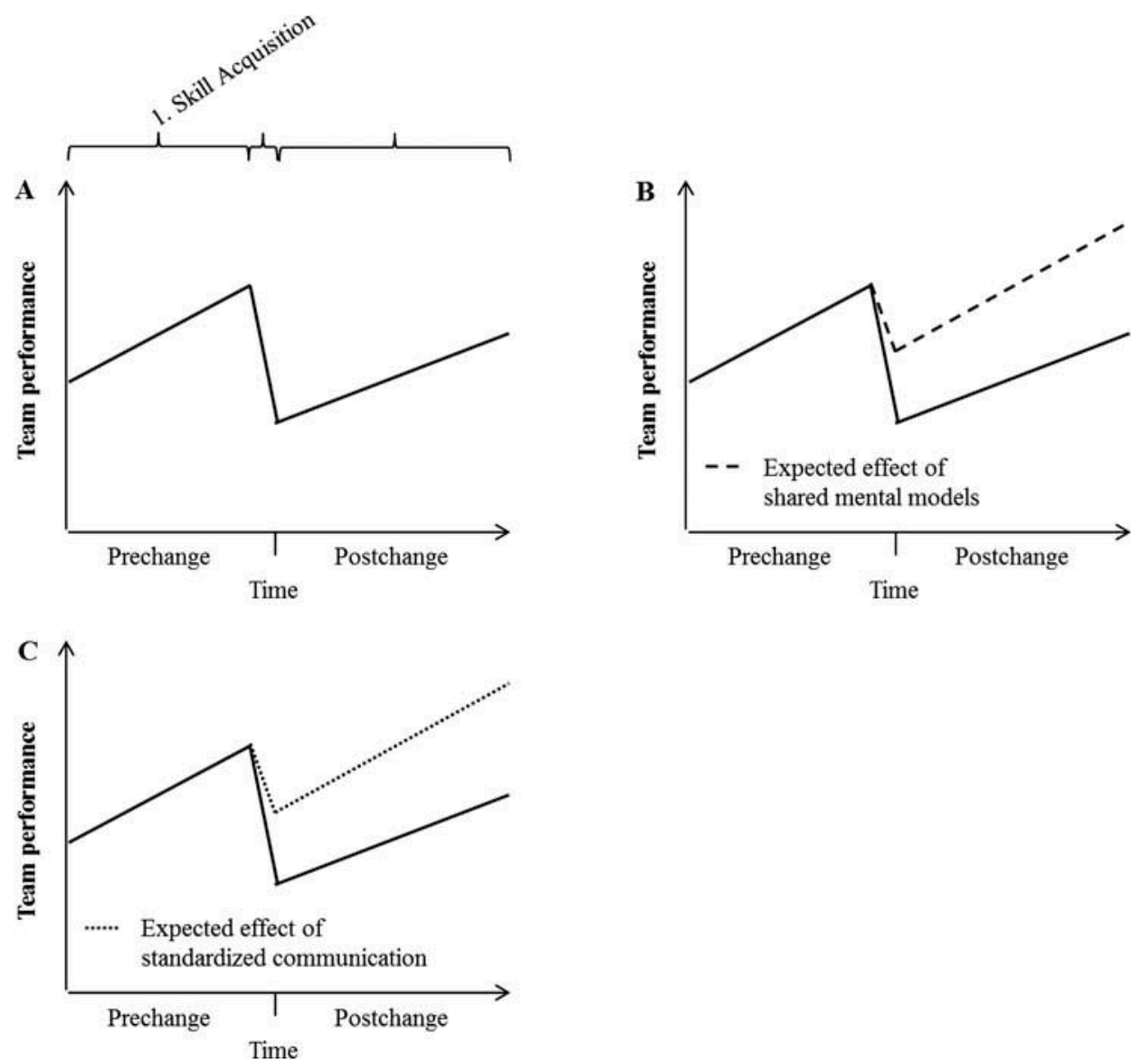

Figure 1. Hypothesized team performance patterns and the effects of shared mental models and standardized communication: (A) mean performance pattern before and after the change (Hypothesis 1), (B) effects of shared mental models on team performance (Hypotheses 2 and 3), and (C) effects of standardized communication on team performance (Hypothesis 4).

prior to the study, which was approved by the local ethics commission.

\section{Team task}

Teams worked on a task within a dynamic environment provided by TeamTris (van der Pal \& Justen, 2011). TeamTris is an adaptation of the well-known Tetris ${ }^{\mathrm{TM}}$ game that allows team members to cooperate with each other. Team-critical aspects built in this task include the need to communicate, develop shared situational awareness, understand role interdependencies among team members, plan ahead, and develop adequate team strategies.

In TeamTris, three team members work together, namely one planner and two controllers. Team members are each seated behind individual personal computers, connected via a local network, and are able to communicate via headsets. Their team goal is the same as in regular Tetris ${ }^{\mathrm{TM}}$, namely to complete lines of blocks at the bottom of the screen. These blocks consist of various geometrical shapes, called game pieces, and are assigned by the planner to each controller. The controllers can then move a game piece until these reach the screen bottom or other game pieces that has descended before them. Positioning of a game piece by a controller is possible via rotation and via horizontal movement within the boundaries of a controller's area. If the planner fails to assign a game piece timely, that is, before the present game piece in a controller's area stopped its downward movement, the system automatically assigns a piece to this controller. Planners have the option to place one piece in a temporary hold if they prefer to assign one or more other pieces first. Identical to players in regular Tetris $^{\mathrm{TM}}$, successful controllers connect falling pieces into horizontal lines of blocks at the bottom of the screen. Full block lines that stretched across the two controller areas disappear and yield points. The game pieces still present in both the controller areas lower by the number of lines that disappear. The team's goal is to clear as many lines as possible.

The shared task requires team members to work together closely as their roles and responsibilities are mutually dependent. The four most important of these dependencies are: (a) penalty points are assigned when the planner fails to timely select a piece so that the system selects one, (b) bonus points are assigned when 
four block lines (across the two areas) are cleared simultaneously, (c) controllers have the option to strategically move a game piece to the area of the other controller, and (d) some pieces cannot be rotated by Controller 1, Controller 2, or both. These game pieces are colour coded. For example, Controller 1 cannot rotate orange $\mathrm{T}$-shaped pieces but are able to rotate a T-shape with another colour.

\section{Implementing the unforeseen change: $A$ simulated partial system failure}

To simulate a partial system failure, the configuration of TeamTris changed in two ways as shown in Figure 2. The general team goal remained the same, but the changes required rethinking and made it necessary to apply new strategies.

First, after the simulated system failure both the controllers could no longer see the areas of both their teammates. The planner kept view of all areas. Second, the colour codes of all game pieces were altered. For example, the L-shape was violet in the prechange configuration and green in the postchange configuration. Despite these drastic changes, team members not necessarily noticed all new aspects immediately. Since the task interface of the planner remained intact, the controllers first needed to inform the planner about this change before the planner could fully understand the new situation. In addition, the new colour codes of the game pieces were particularly relevant for the dysfunctional game pieces. As these only infrequently appeared, an assessment of the situation was required first. Both unforeseen changes were designed to introduce uncoordinated behaviour and confusion, that is, coordination flux. The changes made it more difficult for all team members to use recently learned task strategies and communication habits. The question was whether a team's accurately shared knowledge and standardized communication would support team adaptation and thus lead to a smaller performance drop immediately after the change and a subsequent performance recovery. The specifics of how standardized communication was implemented in this study will be detailed in the next section.

\section{Standardized communication}

Half of the teams in this study were assigned to the standardized communication condition and the other half to the control condition. The purpose of the standardized communication manipulation was to create an effective communication protocol to aid team adaptation to the unforeseen partial system breakdown. In the standardized communication condition, communication protocols were practiced at the beginning of the experimental session. More specifically, practice aimed to teach team members to use standardized terminology
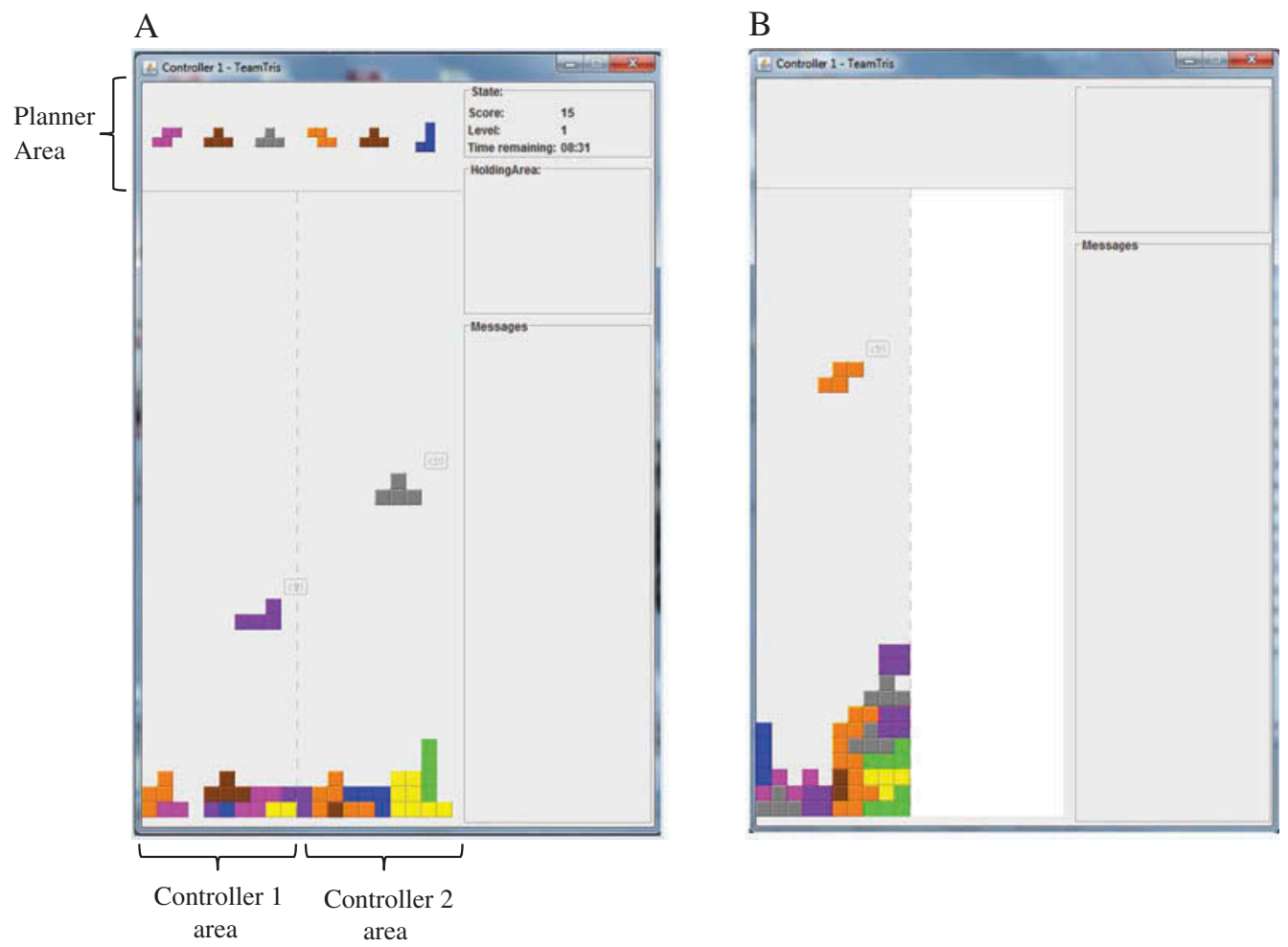

Figure 2. TeamTris interface for Controller 2 before (A) and after the unforeseen change (B). Panel B is seen from the perspective of Controller 2 who is unable to see the areas of the planner and Controller 1. Similarly, Controller 1 was unable to perceive the areas of the teammates, while the planner kept full vision. In Situation B, colour coding was altered for all game pieces. 
for game pieces and standardized communication protocols for the instructions they needed to give each other during task performance. For that purpose, team members were instructed to identify game pieces and name them by their shape instead of their colour. In addition, team members learned to communicate concisely by giving short, standardized instructions to each other. Standardized communication process comprised of three elements: a receiver, an instruction, and a game piece name. For example, in a situation in which Controller 1 would ask the planner to assign an Oshape, Controller 1 would say: "Planner give O." All team members read a training handbook that consisted of three parts. It first explained the terminology of the game pieces according to their geometrical shape. The second part described the instructions protocol, and the final part provided several examples to illustrate the standardized communication flow among team members.

\section{Manipulation check}

To test the effectiveness of the standardized communication training, participants in the standardized communication condition replied to 20 multiple-choice questions. The first 10 questions assessed whether participants could adequately identify a piece based on the terminology and shape recognition. For example: "Which of the following blocks is called an L?" The last 10 questions assessed whether participants had learned to use the trained communication protocols. For example: "If two controllers want to change blocks, which of the following instructions is correct?" We considered the training as effective as teams had an average score of $75 \%(S D=5.55)$ correct answers and $60 \%$ functioned as the minimal criterion.

\section{Procedure}

Upon arrival, participants gave informed consent and completed a demographic questionnaire. Participants were seated behind a personal computer and read a detailed description of their assigned role. Each participant also read the task description of the other roles to ensure that all team members were informed about the general set-up of TeamTris and the different responsibilities within the game. After the instructions, teams in the control condition started the experimental session, whereas teams in the standardized communication condition first received $10 \mathrm{~min}$ of communication training and the subsequent training test, prior to the experimental session.

All teams played six trials of TeamTris, each lasting $10 \mathrm{~min}$. A pilot study revealed that three trials sufficed for a team to become familiar with the game and to improve in performance, which is why three pre- and three post-change trials were chosen. During the first three trials team members played the game in the prechange configuration. The final three trials were played in the changed configuration in which game piece colours were different, and controllers could only view their own area of responsibility. After each trial, team members had a 2-min break to discuss their team performance and task strategy. At the end of the sixth TeamTris trial, shared mental models were assessed.

\section{Measures}

\section{Team performance}

The final score of each TeamTris trial (Trials 1-6) represented team performance, which resulted in six team performance measurements. Each score was composed of reward points (cleared lines) minus the assigned penalty points (nonplanning and collisions of game pieces). A team's final performance score would be negative when the penalty exceeded the reward. Note that we distinguished these scores from combined performance scores before the change (Trials 1-3) and after the change (Trials 4-6) for a more comprehensive presentation of descriptive statistics.

\section{Mental model similarity}

Mental model similarity was assessed by applying a scenario-based approach that has been successfully used in dynamic team environments (Mathieu, Rapp, Maynard, \& Mangos, 2010; Smith-Jentsch, Mathieu, \& Kraiger, 2005). The assumption is that shared mental models are compatible and not identical and therefore should be represented by a consistency rather than a consensus index. For TeamTris (and in dynamic environments as air traffic control), it is important that team members have a similar perception of the prioritization of possible actions and without necessarily knowing the absolute value of these actions (Mathieu et al., 2010).

Task-related similarity. We used the cue-strategy association measure to assess task-related mental model similarity (Smith-Jentsch et al., 2005). Four scenarios represented a possible situation in TeamTris each with four possible actions. Participants rated the desirability of executing each action on a 6-point scale ranging from 1 (very undesirable) to 6 (very desirable). The intermember correlation between these ratings within each team represented task-related mental model similarity.

Team-related similarity. To assess team-related mental model similarity, we applied the positional goal interdependency measure (Smith-Jentsch et al., 2005). We again developed four scenarios, which now each described a possible course of action of one of the team members. Participants then rated the impact of each action on the other roles on a 7-point scale ranging from 1 (strong negative influence) to 7 (strong positive influence). The intermember correlation between these ratings within each team represented team-related mental model similarity. 


\section{Mental model accuracy}

To assess team members' knowledge accuracy, participants filled in a questionnaire consisting of six statements that participants rated with right, wrong, or unknown. A statement regarded task-related and teamwork-related aspects at the same time since this knowledge elements were closely interwoven in the task applied. For example, one statement was "A controller can simultaneously control several blocks in his game field." The accurate answer requires both an understanding of the task rules and a knowledge about other team members' responsibilities. We therefore calculated a general accuracy index rather than team- or task-specific mental model accuracy indices. The calculation was based on an approach used by Cooke and others (2003). Individuals' mental model accuracy was composed of two proportions: the proportion of correctly answered responses and 1 minus the proportion of items rated as unknown. The sum of these two proportions was divided by 2. Equation (1) illustrates this computation with $A(i)$ being the accuracy of person $i$, $C_{i}$ is the number of correct answers given by person $i, U_{i}$ is the number of unknown answers given by person $i$, and $T$ is the total number of possible answer.

$$
A(i)=\frac{\frac{C_{i}}{T}+\left(1-\frac{U_{i}}{T}\right)}{2}
$$

Mental model accuracy of a team was then computed by averaging the individual mental model accuracy scores per team, yielding scores ranging from 0 (no accuracy) to 1 (complete accuracy).

\section{Statistical analysis}

The data were analysed with the nlme package (Pinheiro, Bates, DebRoy, \& Sarkar, 2011) of the open source software R (R Development Core Team, 2011) via the restricted maximum likelihood estimation. Multilevel analysis tested discontinuous growth models describing an initial performance growth, a sudden drop, and a reacquisition of performance. For that purpose three time-based variables representing the initial performance growth and the two subsequent adaptive performance phases were created (Level 1) and nested within team-level variables (Level 2), pertaining to shared mental model measures and standardized communication condition. Details about these variables are provided in the next sections. The analysis involved two steps. First, performance changes over time (across six trials at Level 1) were assessed. Subsequently, shared mental model variables and standardized communication (at Level 2) were added as interaction terms and to function as potential team explanations of the performance changes over time.

\section{RESULTS}

\section{Descriptive statistics, intercorrelations and intraclass correlation}

Table 1 summarizes the descriptive statistics and intercorrelations of the study variables.

Results indicate that only mental model accuracy significantly correlated with performance both before and after the change. In addition, team- and task-related mental model similarity intercorrelated positively. Standardized communication was not related to team performance and to the shared mental model indices.

The intraclass correlation coefficient type I (ICC1; Bliese, 2000) for performance appeared to be .45 . This value represents the proportion of variation in team performance explained by differences between teams across the six task trials. This substantial variance among teams justified further analysis of team performance changes over time.

\section{Level 1 analysis: Describing team performance changes over time}

The analysis that allowed team performance to vary across time was meant to test the first hypothesis, namely whether team adaptation would become discernible after an initial SA by a sudden drop in performance after the unforeseen change and a subsequent RA during the trials

TABLE 1

Means, standard deviations, and intercorrelations of study variables

\begin{tabular}{|c|c|c|c|c|c|c|c|c|}
\hline Variable & $M$ & $S D$ & 1 & 2 & 3 & 4 & 5 & 6 \\
\hline 1. Prechange performance & 266.50 & 405.61 & - & & & & & \\
\hline 2. Postchange performance & 383.15 & 359.72 & $.66^{* *}$ & - & & & & \\
\hline 3. Task-related MM similarity & .52 & .16 & .26 & .24 & - & & & \\
\hline 4. Team-related MM similarity & .36 & .23 & .16 & .26 & $.47 *$ & - & & \\
\hline 5. MM accuracy & 8.92 & 1.48 & $.80 * *$ & $.74 * *$ & .08 & .15 & - & \\
\hline 6. Standardized communication & .50 & .51 & .31 & .18 & .14 & -.16 & .29 & - \\
\hline
\end{tabular}

$* p<.05$ (two-tailed), $* * p<.01$ (two-tailed).

$N=20$. Prechange performance $=$ Trials $1-3$; postchange performance $=$ Trials $4-6 ; \mathrm{MM}=$ mental model; standardized communication was coded as follows: $0=$ control, $1=$ standardized communication. 
TABLE 2

Coding of change variables in the discontinuous growth model

\begin{tabular}{|c|c|c|c|c|c|c|c|}
\hline \multirow[b]{2}{*}{ Variables } & \multicolumn{6}{|c|}{ TeamTris session } & \multirow[b]{2}{*}{ Interpretation } \\
\hline & 1 & 2 & 3 & 4 & 5 & 6 & \\
\hline \multicolumn{8}{|c|}{ Coding of change variables } \\
\hline SA & 0 & 1 & 2 & 3 & 4 & 5 & Linear performance increase across all six sessions \\
\hline TA & 0 & 0 & 0 & 1 & 1 & 1 & Drop in performance immediately after the change \\
\hline RA & 0 & 0 & 0 & 0 & 1 & 2 & $\begin{array}{l}\text { Linear performance increase after the change relative to performance before } \\
\text { the change }\end{array}$ \\
\hline SA2 & 0 & 1 & 2 & 2 & 2 & 2 & Linear performance increase before the change \\
\hline $\mathrm{SA} 2^{2}$ & 0 & 1 & 4 & 4 & 4 & 4 & Quadratic increase before change \\
\hline $\mathrm{RA}^{2}$ & 0 & 0 & 0 & 0 & 1 & 4 & Quadratic increase after change \\
\hline
\end{tabular}

$\mathrm{SA}=$ skill acquisition; $\mathrm{TA}=$ transition acquisition; $\mathrm{RA}=$ reacquisition adaptation .

after the change. These subsequent phases were captured and tested by three change variables: SA - a linear increase of performance; TA - a main difference before and after the change; and RA coded as a linear increase in performance after the change. The coding schemes of SA, TA, and RA are presented in Table 2 (Lang \& Bliese, 2009).

The results of this analysis are presented in Table 3. They show a significant increase in the initial SA, a significant negative effect of TA, and a less strongly significant negative effect of RA during the postchange phase. The outcomes confirm the first hypothesis and indicate that the two phases of adaptation, which have been established for individual adaptive performance, also apply to adaptive team performance. The predicted values of the model as depicted in Figure 3 show that team performance initially improved, then suddenly dropped after the change, and slowly increased again after the change.

\section{Testing for curvilinear changes in time}

Generally, learning curves of complex skills often show nonlinear changes as they tend to rise more steeply in the beginning but reach an asymptote during the learning process (e.g., Oprins, Burggraaff, \& Van
Weerdenburg, 2006). To test for these potential nonlinear changes in our data, we also modelled curvilinear performance changes by adding a second time variable for quadratic SA $\left(\mathrm{SA}^{2}\right)$ and a quadratic term for RA $\left(\mathrm{RA}^{2}\right.$; see Table 2). The results in Table 3 indicate that adding the quadratic terms of SA $\left(\mathrm{SA}^{2}\right)$ and $\mathrm{RA}\left(\mathrm{RA}^{2}\right)$ had no main effects on performance and did not improve the model fit. Therefore, we continued the analysis with the simple linear model only.

\section{Testing for team differences}

It was subsequently tested whether changes in performance were better explained when allowing variation of performance across teams and per adaptation phase. We contrasted this model with the previous one via loglikelihood ratio tests (Bliese \& Ployhart, 2002; Lang \& Bliese, 2009), which was performed per change adaptation phase. However, log-likelihood ratio tests for the simple linear models did not reveal significant results for SA: $\chi^{2} \operatorname{diff}(2)=2.13, p>.05$; TA: $\chi^{2} \operatorname{diff}(2)=4.92$, $p=.09$; and RA: $\chi^{2} \operatorname{diff}(2)=3.32, p=.10$. These results show that the fit of each model does not improve by allowing the performance to vary across teams to account for potential team differences.

TABLE 3

Discontinuous mixed-effects growth Level 1 models predicting change in team performance

\begin{tabular}{|c|c|c|c|c|c|c|}
\hline \multirow[b]{2}{*}{ Variables DV: Team Performance } & \multicolumn{3}{|c|}{ Model 1 (linear model) } & \multicolumn{3}{|c|}{ Model 2 (curvilinear model) } \\
\hline & Coefficient & $S E$ & $t$ & Coefficient & $S E$ & $t$ \\
\hline \multicolumn{7}{|l|}{ Fixed effects } \\
\hline Intercept & -6.37 & 29.95 & $-0.21^{\mathrm{a}}$ & -8.45 & 33.10 & $-.26^{\mathrm{b}}$ \\
\hline SA & 95.20 & 14.55 & $6.55^{\mathrm{a}^{* *}}$ & 107.70 & 51.19 & $1.88^{\mathrm{b}^{*}}$ \\
\hline TA & -174.02 & 40.15 & $-4.33^{\mathrm{a}^{* *}}$ & -178.20 & 61.43 & $-2.90^{\mathrm{b} * *}$ \\
\hline RA & -72.70 & 22.84 & $-3.18^{\mathrm{a}^{* *}}$ & -122.60 & 80.88 & $-1.52^{\mathrm{b}}$ \\
\hline Quadratic SA2 $^{2}$ & & & & -6.25 & 27.47 & $-0.23^{\mathrm{b}}$ \\
\hline Quadratic $\mathrm{RA}^{2}$ & & & & 18.70 & 27.47 & $.68^{\mathrm{b}}$ \\
\hline
\end{tabular}

$N=20 . k=60 . \mathrm{SA}=$ skill acquisition; $\mathrm{TA}=$ transition adaptation; $\mathrm{RA}=$ reacquisition adaptation.

${ }^{\mathrm{a}} d f=97 ;{ }^{\mathrm{b}} d f=95$.

$* p<.05$ (two-tailed). $* * p<.01$ (two-tailed). 


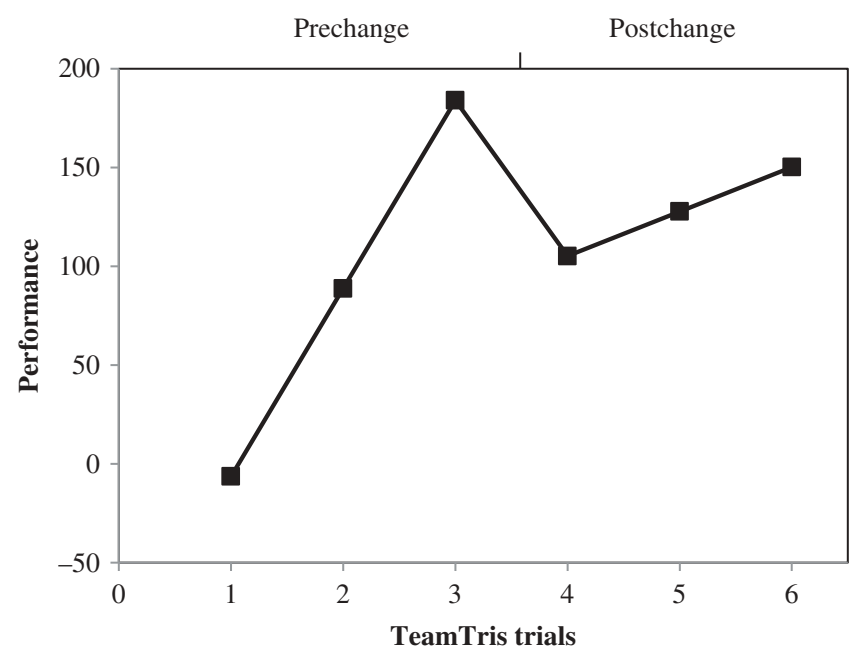

Figure 3. Team performance as a function of time, before and after the unforeseen change (partial system failure).

To verify potential impacts of shared knowledge and standardized communication on team performance over time, we added Level 2 predictors as interaction terms to our current model. These cross-level interactions are permitted without significant intercept variation (group differences) when the expectations have sufficient theoretical backup (LaHuis \& Ferguson, 2009; Lang \& Bliese, 2009; Snijders \& Bosker, 1999). Level 2 predictors pertain to group characteristics that were measured once and are independent of time. We were interested whether these team characteristics would interact with the time variable to explain the change of performance over time. The specific purposes of this Level 2 analysis were first to examine the potential effect of team members' shared knowledge on team performance after the change and, second, to detect potential effects of standardized communication in adaptive team performance.

\section{Level 2 analysis: Explaining team performance via cross-level interactions}

We built four separate discontinuous mixed-effect models to test cross-level interactions to explain performance differences over time among teams. Each model tested the linear effects of each of the three subsequent phases, added by one of the four team-level (Level 2) variables, (a) task-related mental model similarity, (b) team-related mental model similarity, (c) mental model accuracy, or (d) standardized communication. The results of these models are shown in Table 4.

These results show that mental model similarity pertaining to both task and team did not relate to team performance and had no further influence in adaptive team performance. This implies as shown in Figure 4 that teams perform equally well throughout the six TeamTris trials irrespective of the degree of the similarity of team members' task (Figure 4A) and team
(Figure 4B) mental models. Results further reveal that mental model accuracy leads to a general higher team performance and teams with more accurate shared knowledge also perform relatively higher after the unforeseen change (Figure 4C). This means that these teams have an initial performance advantage and show a relatively smaller drop in performance after the change. However, the cross-level interaction of accuracy with each single time variable, representing each of the three change adaptation phases, was not significant. In addition, the standardized communication manipulation was not related to team performance or to team adaptation after the unforeseen change (Figure 4D). Higher-order interactions that combined shared mental models and standardized communication with each time variable were neither significant. The discussion section will elaborate on the potential implications of these results for further study and possible applications.

\section{DISCUSSION}

The present study aimed to shed more light on the temporal nature of adaptive team performance and the potential benefits of shared knowledge and standardized communication. For that purpose 20 teams first performed a collaborative task in a dynamic task environment and were subsequently confronted with an unforeseen change that was implemented as a partial system failure. The results contribute to a better understanding of adaptive team performance. We could confirm that subsequent phases of adaptation observed in individuals (Lang \& Bliese, 2009) also apply to teams. Furthermore, this study affirms that mental model accuracy within a team improved performance in all phases of adaptive team performance and that team performance remains relatively high after an unforeseen change in the task environment. Accuracy of shared knowledge, however, did not specifically affect specific phases of adaptive team 
TABLE 4

Discontinuous mixed-effects growth Level 2 model predicting change in team performance as a function of study variables

\begin{tabular}{|c|c|c|c|c|}
\hline \multirow[t]{2}{*}{$D V:$ Team performance } & \multirow[t]{2}{*}{ Coefficient (SE) } & \multicolumn{3}{|c|}{ Coefficient (SE) of time variable } \\
\hline & & $S A$ & $T A$ & $R A$ \\
\hline Model 1: task-related mental model similarity & & $43.04(51.69)$ & $-68.52(144.27)$ & $-2.07(82.49)$ \\
\hline Task-related mental model similarity & $122.51(201.07)$ & & & \\
\hline $\mathrm{SA} \times$ task-related mental model similarity & $100.22(95.37)$ & & & \\
\hline $\mathrm{TA} \times$ task-related mental model similarity & $-202.69(266.19)$ & & & \\
\hline RA task-related mental model similarity & $-135.69(152.19)$ & & & \\
\hline Model 2: team-related mental model similarity & & $116.09 * *(28.36)$ & $-244.14 * *(77.20)$ & $-80.74(44.75)$ \\
\hline Team-related mental model similarity & $149.95(134.57)$ & & & \\
\hline $\mathrm{SA} \times$ team-related mental model similarity & $-57.80(66.81)$ & & & \\
\hline $\mathrm{TA} \times$ team-related mental model similarity & $193.97(181.89)$ & & & \\
\hline $\mathrm{RA} \times$ team-related mental model similarity & $22.23(105.44)$ & & & \\
\hline Model 3: mental model accuracy & & $55.40(94.51)$ & $-73.08(256.79)$ & $65.71(143.32)$ \\
\hline Mental model accuracy & $68.85(13.98)^{* *}$ & & & \\
\hline $\mathrm{SA} \times$ mental model accuracy & $4.46(10.46)$ & & & \\
\hline $\mathrm{TA} \times$ mental model accuracy & $-11.32(28.43)$ & & & \\
\hline RA $\times$ mental model accuracy & $-15.52(15.87)$ & & & \\
\hline Model 4: standardized communication & & $89.01 * *(20.72)$ & $161.32 * *(57.66)$ & $-46.55(31.82)$ \\
\hline Standardized communication & $70.13(59.11)$ & & & \\
\hline $\mathrm{SA} \times$ standardized communication & $12.20(29.30)$ & & & \\
\hline $\mathrm{TA} \times$ standardized communication & $-25.40(81.55)$ & & & \\
\hline $\mathrm{RA} \times$ standardized communication & $-52.30(45.01)$ & & & \\
\hline
\end{tabular}

$N=20 . k=60 . \mathrm{SA}=$ skill acquisition; $\mathrm{TA}=$ transition adaptation; $\mathrm{RA}=$ reacquisition adaptation. Communication was coded as follows: $0=$ control, $1=$ training.

** $p<.01$ (two-tailed).

performance. Furthermore, the present results did not support the assumptions that mental model similarity and standardized communication protocols affect adaptive team performance after an unforeseen unique change in the task environment. These results and their implications are discussed in more detail.

\section{Theoretical implication}

Team adaptation to an unforeseen change can be described by two consecutive phases, namely a sudden performance drop (transition phase) followed by a reacquisition phase discernible by a steady increase in performance. The phases following an unforeseen change have previously been found in individuals (Lang \& Bliese, 2009) but provide new insight in team research. Although it has been shown that team members experience a sudden performance drop after a team member change (Summers et al., 2012), the present study is unique in that team members have to deal with a partial system breakdown. In addition, the study adds value to prevailing literature by showing the usefulness of discontinuous growth modelling in a team context. This methodological approach helps to better understand the temporal mechanisms of adaptive performance pattern.

The approach is also useful to test influential factors of team performance during distinctive adaptive phases. This is important because the impact of a specific factor may differ depending on the adaptive phase under investigation (Lang \& Bliese, 2009). In the present study the mechanisms and processes pertaining to standardized communication and two properties of shared knowledge were investigated during both phases to test aspects of contemporary models of team adaptation (Burke et al., 2006; Kozlowski et al., 1999; Randall et al., 2011; Rosen et al., 2011). Specifically, we have tested empirically Burke et al.'s (2006) assumption that adaptive team performance is impossible without shared mental models among team members. The investigation of the role of team knowledge and communication in adaptation also differs from recent empirical research that assessed team adaptation in relation to coordination (Summers et al., 2012) and strategy mental models (Randall et al., 2011).

The data reveal that mental model accuracy improves pre- and post-change team performance. This finding extends previous studies on the positive relationship between shared knowledge and team performance (Kozlowski, Watola, Jensen, Kim, \& Botero, 2009; Langan-Fox, Sankey, \& Canty, 2009; Mathieu et al., 2010; Mohammed et al., 2010; Resick et al., 2010) and provides additional detail to the role of shared mental models in adaptive team performance (Baard et al., 2014; Burke et al., 2006; Kozlowski et al., 2009; Rosen et al., 2011). The results of similarity of task- and team-related mental models show that these knowledge structures have no significant effect on performance before or after the unforeseen 
A
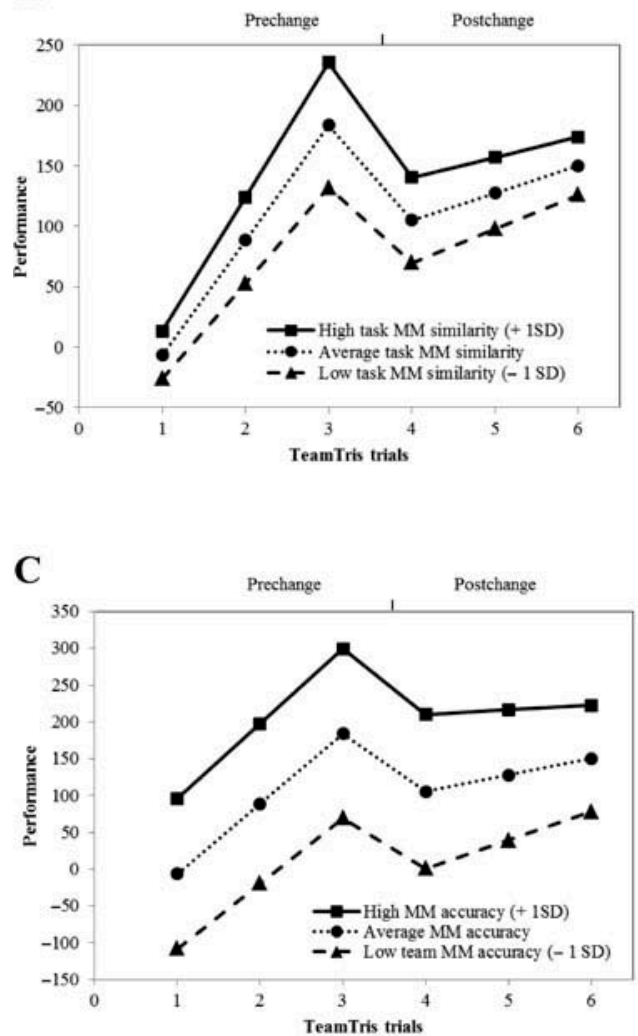

B

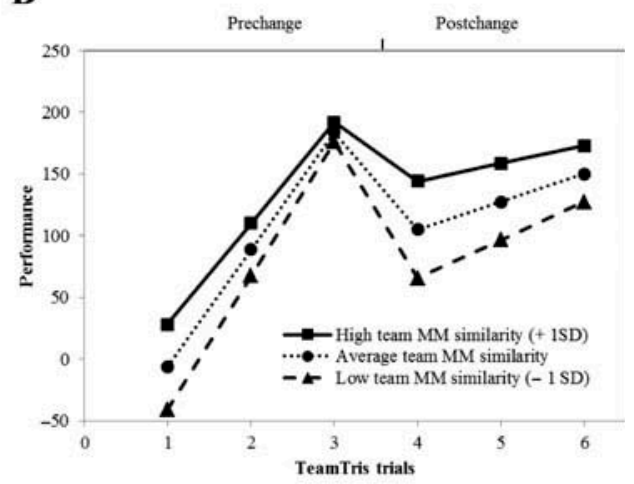

D

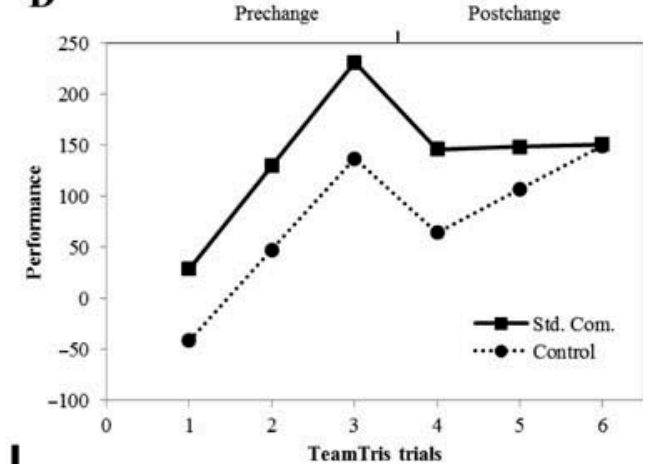

Figure 4. Team performance as a function of time (horizontal axes) and task-related mental model similarity (Panel A), team-related mental model similarity (Panel B), mental model accuracy (Panel C), and standardized communication (Panel D). MM = mental model; Std. Com. $=$ standardized communication.

change. These findings support the idea that effective team members not necessarily need both accurate and similar knowledge structures but that mental model accuracy only can benefit team performance of tasks that can be solved in multiple ways (Resick et al., 2010). Also, they stress the importance to distinguish accuracy from similarity of mental models to understand adaptive team performance (Baard et al., 2014; Burke et al., 2006; Randall et al., 2011; Rosen et al., 2011).

The results add further detail to the notion that mental model accuracy is pivotal in adaptive team performance (e.g., Burke et al., 2006; Randall et al., 2011) and has a function in minimizing initial confusion after a change and in subsequent rapid strategy selection (Rico et al., 2008). However, the present findings imply that the recent suggestion that mental model similarity are not necessarily beneficial to adaptive team performance (Baard et al., 2014; Marks et al., 2001) may be true. Team members who have similar knowledge may be unable to create essential and new shared knowledge structures if the altered new situation calls for alternative strategies. The reason for this is that these teams may be less sensitive to detecting and diagnosing changes in their environment and are therefore less flexible to develop new plans and strategies (Uitdewilligen et al., 2010). Based on this reasoning, similar knowledge structures may fail to aid adaptive team performance after an unforeseen change (Audia, Locke, \& Smith, 2000; Uitdewilligen et al., 2013, 2010).

An important question in the present study was whether standardized communication would help teams to sustain communication patterns after the unforeseen partial system failure. We found no effect of standardized communication on minimizing the performance drop after the change and on the reacquisition of skills in the new situation. This is in line with the notion that teams will experience a coordination flux after the change (Summers et al., 2012), which makes it impossible to reapply learned communication skills. The communication protocols applied in our study focused on concise systematic communication pertaining to the geometry of the game pieces. The unforeseen change included a radical change of colour coding of game pieces, added by a partial visual occlusion of the game area on screen. This combination apparently created a coordination flux (Baard et al., 2014; Burke et al., 2006; Randall et al., 2011; Rosen et al., 2011) that sufficed to make standardized communication ineffective. In addition to previous research, which showed the negative effects of task changes on coordination behaviour (Summers et al., 2012), the present study contributes to the literature by implying negative effects on team communication. 
The present study stands somewhat apart from most team adaptation studies in that the sudden change we induced pertains to a unique partial system failure (Weick, 1985; Weick \& Roberts, 1993). Such a failure is feared by most organizations (Bainbridge, 1983) and especially when it is costly and difficult to diagnose and repair within a short period of time (Marks et al., 2002). It has been long known that it is hard to train employees to handle low-frequent or even unique failures (Bainbridge, 1983). The present approach adds to this literature as it shows the limits of the potential benefits of teams in terms of shared knowledge and standardized communication. Further research should continue with finding those aspects that significantly aid adaptive team performance, such as individual characteristics or team situation awareness (Burke et al., 2006).

\section{Practical implications}

A number of studies claim that team adaptation training can be efficient in facilitating stable team performance, even in novel situations (e.g., Gorman, Cooke, \& Amazeen, 2010; Salas, Nichols, \& Driskell, 2007). It is indeed possible that standardized communication training in the present study had certain positive effects as suggested in the literature (Burke et al., 2006; Kanki et al., 1991; Salas et al., 2007) but that these effects were nullified by negative aspects such as cognitive inflexibility (Gersick, 1988; Stachowski et al., 2009; Summers et al., 2012). Possible positive effects of standardized communication refer to the common understanding within a team about the interaction between team members. This should provide a robust basis that remains usable after the unforeseen change. Potential negative effects of standardized communication include the difficulties that team members have with discarding recently learned patterns even though they are less appropriate in the new situation. Further research is needed to reveal such a potential negation mechanism or confirm that the unforeseen change in the present study caused a large part of the recently acquired knowledge to become redundant and unsuited to effectively adapt to the induced partial system failure.

The present outcomes show that a standardized communication intervention may be quite hard to realize. Organizations often believe that existing communication protocols are adequate for any (also a unique unforeseen) situation, so that adaptation of communication is unnecessary. The present study suggests that such an approach may be rather unrealistic. Unforeseen situations pertaining to unique failures and limitations to automated systems are inherently difficult to predict (Bainbridge, 1983; Weick, 1985; Weick \& Roberts, 1993). This makes it quite difficult to design adequate training to prepare teams for all possible environmental events (Marks et al., 2000). Consistent with this line of thinking is the finding that procedural training, in which team members learn to follow specific procedures, can result in poor adaptation ability in changing and unforeseeable task environments (Gorman et al., 2010).

Other types of interventions may include training in applying strategies to give up formally successful routines and learned behaviour at an appropriate time. Teams should be able to timely appraise the new situation and decide that it asks for new behavioural patterns (Burke et al., 2006; Kraiger, Ford, \& Salas, 1993). These ideas could contribute to further improve crew resource management training, which still has inconsistent effects on learning and behavioural change (Salas, Wilson, Burke, \& Wightman, 2006). A potential instructional method is to use various strategies in a flexible way. The so-called 4C/ID model propagates schema construction for nonrecurrent aspects of the task (Van Merriënboer \& Dijkstra, 1997). Schemas are knowledge structures that enable to apply knowledge and skills effectively and are believed to function in a wide variety of real-life situations. Knowledge contents in a schema are rather abstract, less situation, and context specific and may apply to a variety of known and unknown situations. Future research should investigate the effectiveness of these notions in team adaptation.

\section{Limitations}

The present laboratory study aimed to understand team processes as a preparation to test these in the field. The study therefore had an inherently limited external validity with undergraduate students who worked together on a laboratory team tasks. Specifically, the task environment was not able to fully approach the safety-critical aspects that are common in so-called action team tasks (e.g., air traffic control). Note, however, that the task was quite complex as teams did not reach an asymptote in their learning curves as it is typical in real teams. In addition, a lack of external validity is inherent to laboratory studies, but these studies are needed to develop a good understanding of team processes before we can test these in the field (Zijlstra, Waller, \& Phillips, 2012). Future research should reveal whether the present findings on adaptive team performance can be replicated in field settings. In addition, future research should replicate the study with a larger sample size to confirm the generalizability of the present results.

Another potential limitation of the present study was the restricted period of time. In total the experimental session lasted six times $10 \mathrm{~min}$ of game play. It is possible that the number of trials may have been insufficient to explain performance changes by shared knowledge or by standardized communication training condition. However, a pilot study showed that team performance improved considerably across three trials. And despite the short duration of each trial, the results show a clear change in team success over time. This implies that some team processes were effectively at 
work. In addition, freshly resembled teams may work in comparable settings in which efficient teamwork is required in a short period of time without extensive training possibilities. The present results are specifically relevant for such settings.

Similarly, mental model similarity may not have influenced adaptive team performance because these knowledge structures require time to develop while the present cooperation within a team lasted relatively short (e.g., Mathieu et al., 2010). However, the obtained values for mental model similarity in the present study were not particularly low as compared to other studies. Still, the applied measures of shared knowledge may have been too insensitive to detect differences (Mohammed et al., 2010; Resick et al., 2010). This may pertain not only to the type of measurement but also to what the measure represents. There are various types of measurement. Shared mental models have been appraised via questionnaires, concept maps, or association ratings (Mohammed, Klimoski, \& Rentsch, 2000). A recent meta-analysis revealed that measurements of the structure and organization of knowledge are most predictive for team processes but that all types of measurements are equal in predicting team performance (DeChurch \& Mesmer-Magnus, 2010). In predicting team adaptation in decision-making teams, structural network metrics seems to be most valid (Resick et al., 2010). It is however unclear whether this holds in other types of teams. The method used in the present study (cue-strategy association and positional goal interdependency measure) was carefully chosen as it was believed to be appropriate to predict adaptive team performance of action teams in a dynamic environment, in which a number of alternative actions can be effective (Mathieu et al., 2010).

A related limitation is the measurement of mental model accuracy that did not differentiate between taskand teamwork-related aspects. The results imply that the degree to which team members share accurate knowledge in general positively affects adaptive team performance. Future research should however show whether this results also hold true for more specific forms of knowledge accuracy among team members, that is, knowledge that is related to the task or teamwork.

\section{CONCLUSION}

In sum, this study investigated the discontinuous development of performance through subsequent phases to examine adaptive team performance after an unforeseen change in the task environment. The results confirm that adaptive team performance is a highly complex process (Burke et al., 2006; Entin \& Serfaty, 1999; Kozlowski et al., 2009; Rosen et al., 2011) and add a unique insight to team adaptation research. The results specifically suggest that a team's knowledge accuracy may benefit performance in all subsequent phases of team adaptation.
Knowledge similarity and recently acquired standardized communication protocols, which are generally thought to be beneficial for team performance (Burke et al., 2006; Entin \& Serfaty, 1999; Kozlowski et al., 2009; Randall et al., 2011; Rosen et al., 2011), are not necessarily adequate if the task environment suddenly changes in unforeseen and unique ways. To make adaptive team performance to these changes successful, a team needs to train in updating shared knowledge and standardized communication beyond the change (Audia et al., 2000; Gersick, 1988; Stachowski et al., 2009; Uitdewilligen et al., 2013) and to quickly recuperate and develop new knowledge and strategies to regain maximum performance.

\section{ORCID}

Pia C. Sander (D) http://orcid.org/0000-0001-8717-537X

\section{REFERENCES}

Ackerman, P. L. (1992). Predicting individual differences in complex skill acquisition: Dynamics of ability determinants. Journal of Applied Psychology, 77, 598-614. doi:10.1037/0021-9010.77.5.598

Audia, P. G., Locke, E. A., \& Smith, K. G. (2000). The paradox of success: An archival and a laboratory study of strategic persistence following radical environmental change. Academy of Management Journal, 43, 837-853. doi:10.2307/1556413

Baard, S. K., Rench, T. A., \& Kozlowski, S. W. J. (2014). Performance adaptation: A theoretical integration and review. Journal of Management, 40, 48-99. doi:10.1177/0149206313488210

Bainbridge, L. (1983). Ironies of automation. Automatica, 19, 775-779. doi:10.1016/0005-1098(83)90046-8

Bliese, P. D. (2000). Within-group agreement, non-independence, and reliability: Implications for data aggregation and analysis. In K. J. Klein \& S. W. J. Kozlowski (Eds.), Multilevel theory, research, and methods in organizations: Foundations, extensions, and new directions (pp. 349-381). San Francisco, CA: Jossey-Bass.

Bliese, P. D., \& Ployhart, R. E. (2002). Growth modeling using random coefficient models: Model building, testing, and illustration. Organizational Research Methods, 5, 362-387. doi:10.1177/ 109442802237116

Burke, C. S., Stagl, K. C., Salas, E., Pierce, L., \& Kendall, D. (2006). Understanding team adaptation: A conceptual analysis and model. Journal of Applied Psychology, 91, 1189-1207. doi:10.1037/ 0021-9010.91.6.1189

Cannon-Bowers, J. A., \& Salas, E. (1998). Individual and team decision making under stress: Theoretical underpinnings. In J. A. Cannon-Bowers \& E. Salas (Eds.), Making decisions under stress. Implications for individual and team training (pp. 17-38). Washington, DC: American Psychological Association.

Cannon-Bowers, J. A., \& Salas, E. (2001). Reflections on shared cognition. Journal of Organizational Behavior, 22, 195-202. doi: $10.1002 /$ job. 82

Cannon-Bowers, J. A., Salas, E., \& Converse, S. (1993). Shared mental models in expert team decision making. In N. Castellan (Ed.), Individual and group decision making (pp. 221-246). Hillsdale, NY: Erlbaum.

Chan, D. (2000). Understanding adaptation to changes in the work environment: Integrating individual difference and learning perspectives. In G. R. Ferris (Ed.), Research in personnel and human resources management (pp. 1-42). Oxford: JAI Press/Elsevier.

Cooke, N. J., Kiekel, P. A., Salas, E., Stout, R., Bowers, C., \& CannonBowers, J. A. (2003). Measuring team knowledge: A window to the 
cognitive underpinnings of team performance. Group Dynamics: Theory, Research, and Practice, 7, 179-199. doi:10.1037/ 1089-2699.7.3.179

DeChurch, L. A., \& Mesmer-Magnus, J. R. (2010). Measuring shared team mental models: A meta-analysis. Group Dynamics: Theory, Research, and Practice, 14, 1-14. doi:10.1037/a0017455

Edwards, B. D., Day, E. A., Arthur, W., \& Bell, S. T. (2006). Relationships among team ability composition, team mental models, and team performance. Journal of Applied Psychology, 91, 727-736. doi:10.1037/0021-9010.91.3.727

Entin, E. E., \& Serfaty, D. (1999). Adaptive team coordination. Human Factors, 41, 312-325. doi:10.1518/001872099779591196

Espevik, R., Johnsen, B. H., \& Eid, J. (2011). Communication and performance in co-located and distributed teams: An issue of shared mental models of team members? Military Psychology, 23, 616638. doi:10.1080/08995605.2011.616792

Gersick, C. J. G. (1988). Time and transition in work teams: Toward a new model of group development. Academy of Management Journal, 31, 9-41. doi:10.2307/256496

Gorman, J. C., Cooke, N. J., \& Amazeen, P. G. (2010). Training adaptive teams. Human Factors, 52, 295-307. doi:10.1177/ 0018720810371689

Hockey, J. (1997). Compensatory control in the regulation of human performance under stress and high workload: A cognitiveenergetical framework. Biological Psychology, 45, 73-93. doi:10.1016/S0301-0511(96)05223-4

Kahneman, D. (1973). Attention and effort. Englewood Cliffs, NJ: Prentice Hall.

Kanki, B. G., Folk, V. G., \& Irwin, C. M. (1991). Communication variations and aircrew performance. The International Journal of Aviation Psychology, 1, 149-162. doi:10.1207/ s15327108ijap0102_5

Keyton, J., \& Beck, S. J. (2010). Perspectives: Examining communication as macrocognition in STS. Human Factors: The Journal of the Human Factors and Ergonomics Society, 52, 335-339. doi: $10.1177 / 0018720810371338$

Kontogiannis, T., \& Malakis, S. (2013). Strategies in controlling, coordinating and adapting performance in air traffic control: Modelling 'loss of control' events. Cognition Technology and Work, 15, 153-169. doi:10.1007/s10111-011-0209-0

Kozlowski, S. W. J., Gully, S. M., Nason, E. R., \& Smith, E. M. (1999). Developing adaptive teams: A theory of compilation and performance across levels and time. In D. R. Ilgen \& E. D. Pulakos (Eds.), The changing nature of performance: Implications for staffing, motivation, and development (pp. 240-292). San Francisco, CA: Jossey-Bass.

Kozlowski, S. W. J., Watola, D. J., Jensen, J. M., Kim, B. H., \& Botero, I. C. (2009). Developing adaptive teams: A theory of dynamic team leadership. In E. Salas, G. F. Goodwin, \& C. S. Burke (Eds.), Team effectiveness in complex organizations: Cross-disciplinary perspectives and approaches (pp. 113-156). New York, NY: Routledge Academic.

Kraiger, K., Ford, J. K., \& Salas, E. (1993). Application of cognitive, skill-based, and affective theories of learning outcomes to new methods of training evaluation. Journal of Applied Psychology, 78, 311-328. doi:10.1037/0021-9010.78.2.311

Kring, J. P. (2005). Communication modality and after action review performance in a distributed immersive virtual environment. Dissertation Abstracts International: Section B: The Sciences and Engineering, 66, 598.

LaHuis, D. M., \& Ferguson, M. W. (2009). The accuracy of significance tests for slope variance components in multilevel random coefficient models. Organizational Research Methods, 12, 418435. doi: $10.1177 / 1094428107308984$

Lang, J. W. B., \& Bliese, P. D. (2009). General mental ability and two types of adaptation to unforeseen change: Applying discontinuous growth models to the task-change paradigm. Journal of Applied Psychology, 94, 411-428. doi:10.1037/a0013803
Langan-Fox, J., Sankey, M. J., \& Canty, J. M. (2009). Human factors measurement for future air traffic control systems. Human Factors, 51, 595-637. doi:10.1177/0018720809355278

LePine, J. A. (2005). Adaptation of teams in response to unforeseen change: Effects of goal difficulty and team composition in terms of cognitive ability and goal orientation. Journal of Applied Psychology, 90, 1153-1167. doi:10.1037/0021-9010.90.6.1153

Lim, B.-C., \& Klein, K. J. (2006). Team mental models and team performance: A field study of the effects of team mental model similarity and accuracy. Journal of Organizational Behavior, 27, 403-418. doi:10.1002/job.387

Malakis, S., Kontogiannis, T., \& Kirwan, B. (2010). Managing emergencies and abnormal situations in air traffic control (part II): Teamwork strategies. Applied Ergonomics, 41, 628-635. doi:10.1016/j.apergo.2009.12.018

Marks, M. A., Mathieu, J. E., \& Zaccaro, S. J. (2001). A temporally based framework and taxonomy of team processes. Academy of Management Review, 356-376. doi:10.5465/AMR.2001.4845785

Marks, M. A., Sabella, M. J., Burke, C. S., \& Zaccaro, S. J. (2002). The impact of cross-training on team effectiveness. Journal of Applied Psychology, 87, 3-13. doi:10.1037/0021-9010.87.1.3

Marks, M. A., Zaccaro, S. J., \& Mathieu, J. E. (2000). Performance implications of leader briefings and team-interaction training for team adaptation to novel environments. Journal of Applied Psychology, 85, 971-986. doi:10.1037/0021-9010.85.6.971

Mathieu, J. E., Heffner, T. S., Goodwin, G. F., Cannon Bowers, J. A., \& Salas, E. (2005). Scaling the quality of teammates' mental models: Equifinality and normative comparisons. Journal of Organizational Behavior, 26, 37-56. doi:10.1002/job.296

Mathieu, J. E., Rapp, T. L., Maynard, M. T., \& Mangos, P. M. (2010). Interactive effects of team and task shared mental models as related to air traffic controllers' collective efficacy and effectiveness. Human Performance, 23, 22-40. doi:10.1080/08959280903400150

Mohammed, S., Ferzandi, L., \& Hamilton, K. (2010). Metaphor no more: A 15-year review of the team mental model construct. Journal of Management, 36, 876-910. doi:10.1177/0149206309656804

Mohammed, S., Klimoski, R. J., \& Rentsch, J. R. (2000). The measurement of team mental models: We have no shared schema. Organizational Research Methods, 3, 123-165. doi:10.1177/109442810032001

Murphy, K. R. (1989). Is the relationship between cognitive ability and job performance stable over time? Human Performance, 2, 183200. doi:10.1207/s15327043hup0203_3

Oprins, E., Burggraaff, E., \& Van Weerdenburg, H. (2006). Design of a competence-based assessment system for air traffic control training. The International Journal of Aviation Psychology, 16, 297-320. doi:10.1207/s15327108ijap1603 4

Pinheiro, J. C., Bates, D. M., DebRoy, S., \& Sarkar, D. (2011). nlme: Linear and nonlinear mixed effects models (Version 3.1-101) [Computer software]. Vienna: $\mathrm{R}$ Foundation for Statistical Computing. Retrieved June 2011, from http://cran.r-project.org/

Randall, K. R., Resick, C. J., \& DeChurch, L. A. (2011). Building team adaptive capacity: The roles of sensegiving and team composition. Journal of Applied Psychology, 96, 525-540. doi: $10.1037 / \mathrm{a} 0022622$

R Development Core Team. (2011). R: A language and environment for statistical computing (Version 2.13.1) [Computer software]. Vienna: R Foundation for Statistical Computing.

Resick, C. J., Dickson, M. W., Mitchelson, J. K., Allison, L. K., \& Clark, M. A. (2010). Team composition, cognition, and effectiveness: Examining mental model similarity and accuracy. Group Dynamics: Theory, Research, and Practice, 25, 274-191. doi:10.1037/a0018444

Rico, R., Sánchez-Manzanares, M., Gil, F., \& Gibson, C. (2008). Team implicit coordination processes: A team knowledge-based approach. The Academy of Management Review, 33, 163-184. doi:10.5465/AMR.2008.27751276

Rosen, M. A., Bedwell, W. L., Wildman, J. L., Fritzsche, B. A., Salas, E., \& Burke, C. S. (2011). Managing adaptive performance in 
teams: Guiding principles and behavioral markers for measurement. Human Resource Management Review, 21, 107-122. doi:10.1016/j. hrmr.2010.09.003

Rouse, W. B., \& Morris, N. M. (1986). On looking into the black box: Prospects and limits in the search for mental models. Psychological Bulletin, 100, 349-363. doi:10.1037/0033-2909.100.3.349

Salas, E., Nichols, D. R., \& Driskell, J. E. (2007). Testing three team training strategies in intact teams: A meta-analysis. Small Group Research, 38, 471-488. doi:10.1177/1046496407304332

Salas, E., Rosen, M. A., Held, J. D., \& Weissmuller, J. J. (2009). Performance measurement in simulation-based training: A review and best practices. Simulation \& Gaming, 40, 328-376. doi:10.1177/ 1046878108326734

Salas, E., Wilson, K. A., Burke, C. S., \& Wightman, D. C. (2006). Does crew resource management training work? An update, an extension, and some critical needs. Human Factors, 48, 392-412. doi: $10.1518 / 001872006777724444$

Salas, E., Wilson, K. A., \& Edens, E. (2009). Crew resource management. London: Ashgate.

Smith-Jentsch, K. A., Mathieu, J. E., \& Kraiger, K. (2005). Investigating linear and interactive effects of shared mental models on safety and efficiency in a field setting. Journal of Applied Psychology, 90, 523-535. doi:10.1037/0021-9010.90.3.523

Snijders, T. A. B., \& Bosker, R. J. (1999). Multilevel analysis: An introduction to basic and advanced multilevel modeling. London: Sage.

Stachowski, A. A., Kaplan, S. A., \& Waller, M. J. (2009). The benefits of flexible team interaction during crises. Journal of Applied Psychology, 94, 1536-1543. doi:10.1037/a0016903

Summers, J. K., Humphrey, S. E., \& Ferris, G. R. (2012). Team member change, flux in coordination, and performance: Effects of strategic core roles, information transfer, and cognitive ability. Academy of Management Journal, 55, 314-338. doi:10.5465/ amj.2010.0175

Uitdewilligen, S., Waller, M. J., \& Pitariu, A. H. (2013). Mental model updating and team adaptation. Small Group Research, 44, 127-158. doi:10.1177/1046496413478205
Uitdewilligen, S., Waller, M. J., \& Zijlstra, F. R. H. (2010). Team cognition and adaptability in dynamic settings: A review of pertinent work. In G. P. Hodgkinson \& J. K. Ford (Eds.), International review of industrial and organizational psychology (Vol. 25). Oxford: Wiley-Blackwell.

van der Pal, J., \& Justen, P. (2011). TeamTris: A research and training paradigm for team work in dynamic environments. Paper presented at the 18th International Conference on Technology Supported Learning \& Training, Berlin.

Van Merriënboer, J., \& Dijkstra, S. (1997). The four component instructional design model for training complex cognitive skills. In R. D. Tennyson \& F. Schott (Eds.), Instructional design: International perspectives. Theory and research (Vol. 1, pp. 427445). Hilsdale, NJ: The four component instructional design model for training complex cognitive skills.

Waller, M. J. (1999). The timing of adaptive group responses to nonroutine events. Academy of Management Journal, 42, 127-137. doi: $10.2307 / 257088$

Weick, K. E. (1985). Cosmos vs. chaos: Sense and nonsense in electronic contexts. Organizational Dynamics, 14, 51-64. doi:10.1016/ 0090-2616(85)90036-1

Weick, K. E., \& Roberts, K. H. (1993). Collective mind in organizations: Heedful interrelating on flight decks. Administrative Science Quarterly, 38, 357-381. doi:10.2307/2393372

Wilson, K. A., Salas, E., Priest, H. A., \& Andrews, D. (2007). Errors in the heat of battle: Taking a closer look at shared cognition breakdowns through teamwork. Human Factors: The Journal of the Human Factors and Ergonomics Society, 49, 243-256. doi:10.1518/001872007X312478

Xin, W., \& Zhiming, W. (2005). Antecedents and consequences of shared mental model in work teams. Acta Psychologica Sinica, 37, $542-549$.

Zijlstra, F. R. H., Waller, M. J., \& Phillips, S. I. (2012). Setting the tone: Early interaction patterns in swift-starting teams as a predictor of effectiveness. European Journal of Work and Organizational Psychology, 21, 749-777. doi:10.1080/1359432X.2012.690399 